\title{
DISCURSO EN RELACION AL CAMBIO DE DIRECTORIO DE LA SOCIEDAD CHILENA DE OBSTEIRICIA Y GINECOLOGIA
}

Quisiera referirme hoy a dos aspectos con motivo del cambio del Directorio de la Sociedad Chilena de Obstetricia y Ginecología. El primero de ellos dice relación con el evento FIGO 2003 y lo que nos correspondió vivir en el Directorio saliente. Pretendo ser breve, porque este tema ha sido suficientemente tratado, y la doctora Ruiz ha expuesto acabadamente al respecto. Nada podría decir, que no se haya dicho antes, a menos que decidiese relatar anécdotas o historias que hoy me parecen más dignas de conversaciones de sobremesa o de cuentos para los nietos. No hay duda alguna de que el evento de la FIGO fue lo mejor que le ha pasado a esta Sociedad probablemente desde su creación. Fue como todos sabemos, el mayor evento de naturaleza alguna que haya tenido lugar en este país, y por las razones antes mencionadas, materia de múltiples publicaciones en periódicos, revistas y televisión, incluyendo reportajes de CNN. Fue, finalmente, inspiración para futuros eventos similares, médicos y no médicos, y colocó a nuestra especialidad en un sitial diferente en el país, en el continente y en el mundo. La influencia país que la realización de este evento tuvo fue de tal magnitud que basta imaginar que si de cada diez personas que vinieron, de los varios miles, una de ellas hable de este país, de su entorno y sus gentes, el efecto multiplicador será inmenso e inimaginable para nuestro futuro.

Para todos nosotros y el directorio saliente, fue un honor y un privilegio haber sido parte de esa historia. Quisiera, sin embargo, y para terminar este tema, destacar una vez más el rol de Mercedes Ruiz en la gestión final y definitiva que permitió la realización exitosa de FIGO 2003 en Santiago. Desde el inicio de los esfuerzos que fueron necesarios para que el Congreso se pudiese realizar, me pareció que el rol de Mercedes Ruiz fue tan importante, que recordé siempre un libro que había leído en mi adolescencia cada vez más lejana. Se trata de una pareja de libros de Stefan Zweig llamados MOMENTOS ESTELARES DE LA HUMANIDAD, donde el autor se refiere a momentos claves de la historia en los que fueron decisi- vos el azar, la presencia de alguien en particular y una serie de hechos que podrían parecer fortuitos, pero que a alguien como yo que no cree mucho en el azar le parece mejor explicación que tales hechos tienen que ver más con los designios de Dios, que con el azar mismo o la conjunción de los astros en el cielo.

En beneficio del tiempo no puedo compartir con ustedes las historias únicas e irrepetibles que Zweig relata, y que son fascinantes, pero quisiera sí leerles la introducción del primero de esos libros: "la estrella del destino que rige a los poderosos y los violentos, año tras año se transforma en la servil esclava de un hombre: César, Alejandro, Napoleón. El destino, elemento imponderable, ama al humano elemental que es semejante a él. En contadas oportunidades en el espacio de los tiempos, en un arrebato de su caprichosa volubilidad, se vincula al azar, en un ser cualquiera. Muy raras veces, maravillosos monumentos de la historia del mundo, el hilo de los hados es captado un momento por una mano indiferente, y ese hombre se siente más temeroso que feliz; un aluvión de responsabilidades se arroja entonces al heroico espectáculo del mundo y la mano permite escapar el hilo que mantenía asido. Muy pocos son los que advertidos de ese azar, lo aprovechan para encumbrarse. Fugaz ese momento en que se discierne la grandeza a los menguados; por cierto que la venturosa suerte no volverá a ellos por segunda vez". Yo sé que hay diferencias entre este párrafo que les he leído y la historia personal de Mercedes Ruiz con relación a esta Sociedad, pero él destaca claramente la importancia que tiene el que en determinados momentos históricos esté allí una persona y no otra.

En la segunda parte de estos minutos quisiera referirme a lo que debemos esperar de nuestra Sociedad en el futuro, y lo que me parece debe ser la misión, en ese sentido, de este o futuros directorios. No pretendo en modo alguno dictar normas sobre lo que creo debe hacerse, ni pretendo dar directrices a otros, porque suficiente tengo con intentar seguir las propias. Es obvio que lo que venga nacerá del trabajo conjunto de este $u$ 
otros directorios, de tal modo que sólo pretendo que consideren lo que viene como una reflexión personal de quién tiene el deseo honesto de que nuestros especialistas sean los mejores del mundo, y de que ellos ayuden a encumbrar a nuestro país al mundo desarrollado.

Cabe reflexionar, porque como sabemos somos hoy testigos de grandes cambios socio culturales, económicos y filosóficos. La salud ha dejado de ser una gracia de Dios y para muchos es más un bien en el que importa la satisfacción del usuario, y, por lo tanto, cambia la relación médicopaciente. Los movimientos de tipo comercial que ocurren en el escenario médico nacional en términos de inversiones, desplazamientos de médicos de un sitio a otro, creación de nuevas escuelas de medicina, compras, ventas y joint ventures son hoy periódicos, frecuentes y rápidos.

Nuestra especialidad, por otra parte, ha perdido el glamour que la caracterizó por décadas. Hoy, los pabellones quirúrgicos son ocupados por las cirugías para tratar la obesidad y por las cirugías plásticas, cada vez más numerosas. La paciente obstétrica y muchas veces, la paciente ginecológica, esperan estar siempre sanas. A diferencia de las enfermedades cardiovasculares $u$ oncológicas, nuestras pacientes esperan que todo resulte siempre perfecto. Todo lo diferente a la perfección es considerado un problema médico. $Y$ si bien el modelo actual es de participación informada que supone que las responsabilidades son compartidas, en este caso por médico y paciente, en la práctica, cuando hay problemas, las responsabilidades son sólo del médico. Existe conciencia, por lo tanto, de los derechos, pero no de los deberes, y las exigencias para ambos son disímiles.

En este año 2004 existen 21 Facultades de Medicina distribuidas en once ciudades de Chile; nueve en Santiago y tres en Concepción. Este año se dispone de 1.500 vacantes aproximadamente. Las dos universidades tradicionales, responsables del $75 \%$ de la producción científica del país, representarán en siete años, sólo el $18 \%$ (270/1500) de los médicos del país. Muchas de estas universidades privadas no desarrollan investigación, sino sólo practican la enseñanza de pregrado.

La formación de especialistas es ciertamente responsabilidad de las Facultades de Medicina. La oferta de programas de especialización debe tener, sin embargo, relación con las necesidades de la población, con la capacidad de los centros calificados para formar nuevos especialistas, con el número y preferencias de los médicos que egresan cada año y que aspiran a especializarse. Es claro que aquí existe un terreno abierto en el que nuestra Sociedad debiera jugar un rol fundamental, al menos, no debería guardar silencio.

Un documento de algunos pocos años atrás firmado por la Sociedad Médica de Santiago, Conacem, Sociedad de Cirujanos de Chile, Asofamech y por el Departamento Científico y Docente del Colegio Médico de Chile, señaló a este respecto que debe darse prioridad a las especialidades que constituyen la medicina clínica general: medicina interna, pediatría y medicina familiar. Es curioso que no se haya considerado a la Obstetricia y Ginecología. Probablemente influyó el hecho de que tales especialistas no estuvieron presentes en ninguna de las instancias que firmaron ese documento. No hay dudas, sin embargo, de que la Obstetricia y Ginecología es base importante de la atención primaria y secundaria de los chilenos. Aún más, es claro a mi modo de ver, que el gineco-obstetra debiera ser por definición el médico general de la mujer, porque en la práctica ha cumplido por siempre ese rol. Sin embargo, los médicos familiares pueden desarrollar muchas de nuestras acciones, y la reflexión, en definitiva, de cuál será el futuro de nuestra especialidad, también corresponde a esta Sociedad.

Hoy en día la rapidez con que avanza la tecnología es impresionante. Cuanto más impresionante es, desde el punto de vista tecnológico, un nuevo recurso diagnóstico, más rápido prolifera y más urgente se hace su aplicación. Si tal recurso produce cuadros de colores, ruidos, gráficos y otros, la impresión tanto para médicos como para pacientes es máxima. El incentivo para tener la nueva tecnología pasa a ser la posibilidad de quedar anticuado, más que la necesidad de ofrecer lo mejor a las pacientes. Es posible, que la incorporación de nuevas tecnologías cuya utilidad no ha sido adecuadamente documentada esté favoreciendo un aumento de las intervenciones. En esta área, hay ciertamente también responsabilidad para esta Sociedad.

Las responsabilidades del gineco-obstetra a medida que avancemos en el siglo XXI cambiarán. Los conocimientos que se le exigirán serán diferentes: ciencias básicas, genética y biología molecular, son disciplinas que los nuevos especialistas deberán comprender a cabalidad, porque serán las que permitirán entender la fisiopatología de numerosos trastornos de la especialidad que hoy no comprendemos. En estas materias, las universidades tienen un rol fundamental, pero 
nuestra Sociedad deberá ser un líder opinante en esos cambios.

Creo que nuestro Directorio en particular, debe responsabilizarse de algunas tareas especificas: la realización de la FIGO 2003 y nuestro posicionamiento en ese organismo exige que hagamos lo posible por mantener un nexo internacional importante. La incorporación de especialistas de provincia y el trabajo conjunto con los de países latinoamericanos es hoy una exigencia para el futuro. El realizar el Congreso Chileno fuera de Santiago y realizar jornadas en el norte o sur del país, me parece también una exigencia ineludible; realizar algunas modificaciones de nuestras reuniones periódicas, de modo de favorecer una asistencia mayor que la pobre asistencia actual, también me parece fundamental. Quizás podemos hacer reuniones de consenso similares a las mesas redondas de años atrás, y quizás, debemos pensar en entregar a diferentes hospitales la responsabilidad de algunas reuniones; el quehacer de la Sociedad debe aunar a las múltiples sociedades satélites que hoy existen; la elección de los directorios de la Sociedad probablemente también debe modificarse, de modo de que un comité de búsqueda integrado por past presidents y otros integrantes distinguidos de la Sociedad sean los que oficialmente busquen, entrevistando a especialistas de diferentes hospitales, a quienes deben dirigir los destinos de la Sociedad en el futuro.

La supervivencia de nuestra Sociedad incluye la revista propia y la realización de un Congreso cada dos años, pero esto está lejos de ser todo. Nuestra Sociedad debe asumir su rol como organismo autónomo, consultor y técnico; debe ser un líder de opinión en lo que a nuestras materias atañe.

Es claro que las tareas son muchas y de gran envergadura. Para su ejecución, un directorio o sus miembros no bastan, y debemos delegar encargos específicos a muchos de ustedes. Las tareas de este o de cualquier grupo no son de unos pocos individuos, sino de todos los que conformamos esta Sociedad. Lo que el futuro nos depare será como siempre nuestra responsabilidad y ella es colectiva en lo que a estas materias se refiere. Lo que les pido hoy, entonces, es que soñemos juntos los cambios que queramos realizar, y que cada vez que alcemos la voz para criticar algo que pudimos hacer mejor, pensemos primero en como podemos colaborar para que la próxima vez los resultados sean mejores.

Martes 6 de Abril de 2004.

Dr. EnRIQUe OyARZún Ebensperger

\section{CUENTA DEL PRESIDENTE DE LA SOCIEDAD CHILENA DE OBSTEIRICIA Y GINECOLOGÍA}

\section{Estimados Consocios:}

De acuerdo a los Estatutos, me corresponde hoy en mi última actividad oficial como Presidente de la Sociedad Chilena de Obstetricia y Ginecología, dar cuenta de la gestión del directorio que he tenido el honor de presidir durante los años 2002 y 2003. La cuenta financiera debería ser presentada por el Sr. Tesorero Dr. Patricio Silva Rojas, quien por razones de fuerza mayor se ha disculpado de su inasistencia y por lo tanto será entregada por el Dr. Eghon Guzmán Bustamante, Secretario General.

REUNIONES DE DIRECTORIO. Durante los años 2002 y 2003 se realizaron 40 reuniones de
Directorio en las que se trataron varios temas relacionado con la marcha de la Sociedad y principalmente nos abocamos a los Cursos precongreso y a incentivar la inscripción de médicos chilenos y extranjeros al Congreso Mundial FIGO 2003.

REUNIONES CIENTIFICAS. Durante el año 2002 se realizaron 16 sesiones científicas en las que se presentaron 28 trabajos, 10 de ellos fueron trabajos de ingreso a la Sociedad de los siguientes médicos:

1. Dr. Jorge Varela P. "CONIZACIÓN POR ASA. Experiencia en el hospital Carlos Van Buren". Servicio de Obstetricia y Ginecología. Hospital Carlos Van Buren de Valparaíso. 